\title{
Two-Dimensional Mathematical Modeling of the Pack Carburizing Process
}

\begin{abstract}
S. SARKAR and G.S. GUPTA
Pack carburization is the oldest method among the case-hardening treatments, and sufficient attempts have not been made to understand this process in terms of heat and mass transfer, effect of alloying elements, dimensions of the sample, etc. Thus, a two-dimensional mathematical model in cylindrical coordinate is developed for simulating the pack carburization process for chromium-bearing steel in this study. Heat and mass balance equations are solved simultaneously, where the surface temperature of the sample varies with time, but the carbon potential at the surface during the process remains constant. The fully implicit finite volume technique is used to solve the governing equations. Good agreement has been found between the predicted and published data. The effect of temperature, carburizing time, dimensions of the sample, etc. on the pack carburizing process shows some interesting results. It is found that the two-dimensional model gives better insight into understanding the carburizing process.
\end{abstract}

DOI: $10.1007 / \mathrm{s} 11661-008-9569-3$

(C) The Minerals, Metals \& Materials Society and ASM International 2008

\section{INTRODUCTION}

PACK carburizing is a process in which ferrous metal is brought into contact with an environment of sufficiently high carbon potential to cause absorption of carbon at the surface and to enable diffusion as a result of the carbon concentration gradient between the surface and the interior of the metal.

The basic reactions are

$$
\begin{gathered}
2 \mathrm{C}+\mathrm{O}_{2} \rightarrow 2 \mathrm{CO} \\
2 \mathrm{CO}+\mathrm{Fe} \rightarrow \mathrm{C}_{\text {active }}+\mathrm{CO}_{2} \\
\mathrm{CO}_{2}+\mathrm{C} \rightarrow 2 \mathrm{CO}
\end{gathered}
$$

The carbon dioxide formed will react with solid carbon to form additional carbon monoxide, but the reaction will stop if equilibrium is reached at a given temperature. Very often energizers are added with carbon to force the reaction in the direction favoring the formation of carbon monoxide. ${ }^{[1]}$ The transport of carbon from the surface of the steel specimen toward the center proceeds through the diffusion mechanism. In the absence of any alloying element, this process depends totally on the diffusion coefficient of carbon in $\gamma$ iron at that temperature.

S. SARKAR, formerly Graduate Student, Department of Materials Engineering, Indian Institute of Science, is Research Scientist, SINTEF Materials and Chemistry, Trondheim, N7465, Norway. G.S. GUPTA, Associate Professor, is with the Department of Materials Engineering, Indian Institute of Science, Bangalore 560 012, India. Contact e-mail: govind@materials.iisc.ernet.in

Manuscript submitted August 21, 2007.

Article published online July 8, 2008
Though the process has some disadvantage over gas carburization, it is still widely used in industry. It is seen that in the case of pack carburizing, especially deep carburizing of highly alloyed steels such as chromiumbearing steels, it is difficult to obtain a case free from heavy carbide networks. ${ }^{[2]}$ Further, it is observed that the major difficulty is to obtain a shallow case depth $\sim 0.0254 \mathrm{~cm}$. To overcome these difficulties, the effect of various factors such as temperature and amount and type of energizer on the nature of the case depth in pack carburization was studied experimentally. ${ }^{[1,2]}$

There have been many theoretical studies on gas carburizing, ${ }^{[3-6]}$ which are mostly associated with onedimensional modeling. However, pack carburizing has rarely been treated theoretically. The effect of chromium and other alloying elements on gas carburization in the one-dimensional model has been studied by few investigators ${ }^{[7,8]}$ Goldstein et al.$^{[4]}$ carried out a simulation to study the importance of the off-diagonal or crossdiffusion coefficient on carbon diffusion. However, they did not include the effect of temperature in their model study. Because the diffusivity is an exponential function of temperature, the assumption of diffusion of carbon at constant temperature may incorporate some error in the result. The dimensions of most of the carburizing parts are such that the effect of diffusion from other directions is not negligible. The effect of alloying elements on pack carburizing in two dimensions has not been studied yet.

In the present work, an attempt is made to study the effect of chromium on pack carburization considering a typical $\mathrm{Fe}-\mathrm{C}-\mathrm{Cr}$ ternary system. The main aim is to study the effect of the second dimension on the massand heat-transfer process during pack carburization. A mathematical model for the process has been developed considering two-dimensional energy and mass (carbon and chromium) balance. Computed results have been compared with the published data available in the literature. 